\title{
Article \\ Study on Dynamic Constitutive Model of Polypropylene Concrete under Real-Time High-Temperature Conditions
}

\author{
Rui Li ${ }^{1}$, Lei Liu ${ }^{1}{ }^{*}$, Huaming An ${ }^{2}$ (D) and Ya Wang ${ }^{1}$ \\ 1 Faculty of Land Resource Engineering, Kunming University of Science and Technology, \\ Kunming 650093, China; ruili@stu.kust.edu.cn (R.L.); wangya1993@dingtalk.com (Y.W.) \\ 2 Faulty of Public Security and Emergency Management, Kunming University of Science and Technology, \\ Kunming 650093, China; huaming.an@kust.edu.cn \\ * Correspondence: kgliulei@kust.edu.cn
}

check for updates

Citation: Li, R.; Liu, L.; An, H.; Wang, Y. Study on Dynamic Constitutive Model of Polypropylene Concrete under Real-Time High-Temperature Conditions. Appl. Sci. 2022, 12, 1482 https://doi.org/10.3390/ app12031482

Academic Editor: Chao-Wei Tang

Received: 12 January 2022

Accepted: 28 January 2022

Published: 29 January 2022

Publisher's Note: MDPI stays neutral with regard to jurisdictional claims in published maps and institutional affiliations.

Copyright: (C) 2022 by the authors. Licensee MDPI, Basel, Switzerland. This article is an open access article distributed under the terms and conditions of the Creative Commons Attribution (CC BY) license (https:// creativecommons.org/licenses/by/ $4.0 /)$.
Abstract: Polypropylene (PP) concrete, a kind of high-performance fiber-reinforced concrete, is widely used in large concrete structures. Studies on the dynamic mechanical properties of polypropylene concrete under temperature-impact load can provide a theoretical basis for research on the structural stability of concrete structures during fires, explosions, and other disasters. The purpose of this paper was to study the dynamic mechanical properties of polypropylene concrete under real-time hightemperature conditions and to establish a dynamic damage constitutive model for polypropylene concrete under real-time high-temperature conditions. In this paper, Split Hopkinson Pressure Bar (SHPB) equipment was used to test the dynamic mechanical properties of polypropylene concrete with different high strain rates under different real-time high temperatures (room temperature, $100{ }^{\circ} \mathrm{C}$, $200{ }^{\circ} \mathrm{C}, 300{ }^{\circ} \mathrm{C}, 400{ }^{\circ} \mathrm{C}, 500{ }^{\circ} \mathrm{C}, 600^{\circ} \mathrm{C}, 700{ }^{\circ} \mathrm{C}$, and $800{ }^{\circ} \mathrm{C}$ ). A modified "Z-W-T" model was used to determine the recursion of the dynamic damage constitutive model of polypropylene concrete under different temperature-impact loads, and the model was compared with the experimental data. The results show that the thermal conditions influenced the chemical composition and microstructure of the polypropylene fiber concrete, which was why the high temperatures had a strong influence on the dynamic mechanical properties of polypropylene concrete. When the heating temperature exceeded $300{ }^{\circ} \mathrm{C}$, although the polypropylene concrete specimen was still able to maintain a certain strength, the dynamic mechanical properties showed a deterioration trend as the temperature increased. The comparation between the experimental data and the fitting curve of the dynamic damage constitutive model showed that the dynamic stress-strain curves could be well matched with the fitting curves of the dynamic damage constitutive model, meaning that this model could describe the dynamic mechanical properties of polypropylene concrete under different real-time high temperatures well.

Keywords: polypropylene concrete; real-time high temperature; SHPB; constitutive model; dynamic mechanical properties

\section{Introduction}

In recent years, a new tendency to add different kinds of materials [1,2], such as carbon nano-fibers [3,4], steel fibers [5], and polypropylene fibers [6], to concrete to improve its mechanical properties has been observed. Polypropylene (PP) fiber concrete [6], a type of high-performance fiber-reinforced concrete, is characterized by its high level of toughness and high tensile strength. In addition, polypropylene fiber-reinforced concrete has less of a risk of cracking when exposed to high temperatures, a benefit from the internal steam pressure caused by the fusion temperature of the polypropylene fiber $\left(170{ }^{\circ} \mathrm{C}\right)$ [7]. The above characteristics make polypropylene fiber concrete appropriate for widespread use in large concrete structures [8], such as in nuclear power protection facilities, military protection facilities, and airport runways. Explosions often occur when concrete structures experience fire-related disasters $[9,10]$, which may engender instability and even 
the collapse of concrete structures due to the high temperatures caused by the flames and the dynamic load caused by the explosions [11]. Studying the dynamic mechanical properties and dynamic damage evolution relationship of concrete materials under high temperatures is of great significance to improve the fire resistance and explosion resistance of concrete structures, allowing the structure's security requirements as well as national defense requirements to be satisfied.

There have been increasing concerns surrounding how the mechanical properties of polypropylene fiber concrete react to thermal effects in recent years. Some related research results have shown that the mechanical properties of concrete specimens are obviously improved when they contain fibers [12-14]. Moreover, the dynamic mechanical properties of polypropylene fiber concrete, such as dynamic compressive strength [15], dynamic tensile strength [16,17], and the dynamic elastic modulus [7], have an obvious thermal effect when affected by high temperatures. In the meantime, some research results have shown that since polypropylene fiber concrete is a brittle material, it is highly sensitive to strain rate [18], and the coupling effect of the thermal and dynamic loads is not a simple summation relationship [19]. Consequently, the thermal effect and strain rate effect cannot be ignored when studying dynamic damage evolution in polypropylene fiber concrete under high temperatures because of the different mechanical properties of polypropylene fiber concrete prepared under different engineering backgrounds [20] due to the structural characteristics of polypropylene fiber concrete.

Since Zhu's [21,22] proposal of an improved Z-W-T non-linear viscoelastic model on the basis of the dynamic mechanical properties of polymers in 1981, the model has been extended to the expression of the mechanical properties of other materials [23-25]. Through further research, other scholars found that the Z-W-T non-linear viscoelastic model can not only better describe the dynamic response phenomenon of soft materials such as polymers, but it can also describe the dynamic mechanical properties of concrete materials [26]. Subsequently, some scholars began to explore a dynamic damage constitutive model of concrete materials with fibers and concrete materials affected by thermal conditions based on those of the Z-W-T non-linear viscoelastic model. Fu [18] studied the dynamic compression behavior of basalt-polypropylene hybrid fiber (HBPRC) and concrete with different matrix strengths was studied by using the split Hopkinson pressure bar, and a dynamic damage constitutive model was proposed based on the principle of damage variable, with the research results showing that the dynamic damage constitutive model that he proposed was better able to describe the stress-strain curves obtained from the experiment. ZHAI [27] studied the influence of high-temperature cold damage on the mechanical properties of concrete and proposed a dynamic nonlinear elastic constitutive equation that considers the cooling effect, with the fitting results of that equation being very close to the experimental results, meaning that it is considered to be able to describe the dynamic mechanical properties of concrete under the corresponding conditions.

To sum up, although the dynamic mechanical properties and dynamic damage evolution models of polypropylene fibers affected by thermal conditions are receiving increased attention, most concrete specimens are heated and then naturally cooled to room temperature during specimen treatment processes in the present research. Moreover, research on the dynamic damage evolution relationship of polypropylene fibers affected by high temperatures also tends to consider the temperature damage and dynamic load damage as a whole, and research on the dynamic damage evolution relationship of polypropylene fiber concrete that considers the coupling effect of temperature and dynamic impact load has rarely been reported upon.

Accordingly, in this paper, a dynamic damage constitutive equation for polypropylene fibers that considers the effects of the temperature and strain rate was constructed. Additionally, modified SHPB dynamic mechanical test equipment was used to test the dynamic impact compression of PP concrete with different impact air pressure grades $(0.4 \mathrm{MPa}$, $0.6 \mathrm{MPa}$, and $0.8 \mathrm{MPa}$ ) under different real-time temperature grades (room temperature, $100{ }^{\circ} \mathrm{C}, 200{ }^{\circ} \mathrm{C}, 300{ }^{\circ} \mathrm{C}, 400{ }^{\circ} \mathrm{C}, 500{ }^{\circ} \mathrm{C}, 600{ }^{\circ} \mathrm{C}, 700{ }^{\circ} \mathrm{C}$, and $800{ }^{\circ} \mathrm{C}$ ) to explore the influence 
of thermal and impact loading on the dynamic mechanical properties of polypropylene (PP) concrete under real-time high-temperature conditions and the dynamic damage evolution relationship of polypropylene fiber concrete in the corresponding environments. In addition, the dynamic damage constitutive equation that was determined for polypropylene fiber was compared to the experimental results to verify the correlation of the dynamic damage constitutive equation.

\section{The Modified Dynamic Constitutive Model of Polypropylene Concrete}

The main expression of the Z-W-T non-linear viscoelastic model (Equation (1)), which is shown in Figure 1a, consists of two parts [28]: one is the transient response element, which is unrelated to the strain rate $\left(E_{0}\right.$ in Figure 1a, part I in Equation (1)), and the other is the transient response, which is related to the strain rate and is composed of two Maxwell elements ( $E_{1}$ and $E_{2}$ in Figure 1a, part II in Equation (1)).

$$
\sigma=\underbrace{E_{0} \varepsilon+\alpha \varepsilon^{2}+\beta \varepsilon^{3}}_{I}+\underbrace{E_{1} \int_{0}^{t} \dot{\varepsilon}(t) \exp \left(-\frac{t-\tau}{\theta_{1}}\right) d \tau+E_{2} \int_{0}^{t} \dot{\varepsilon}(t) \exp \left(-\frac{t-\tau}{\theta_{2}}\right) d \tau}_{I I}
$$

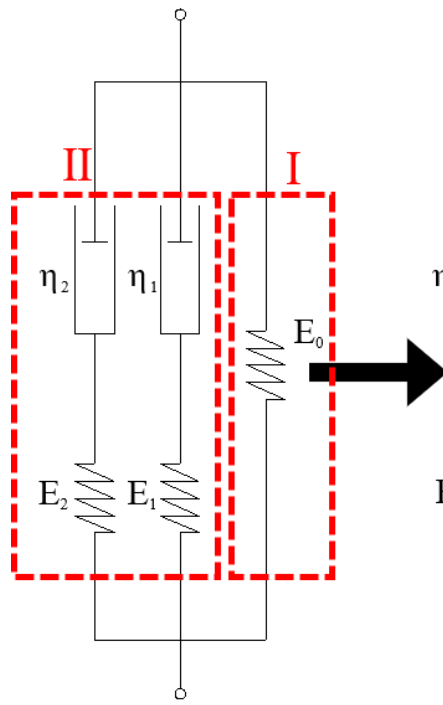

(a)

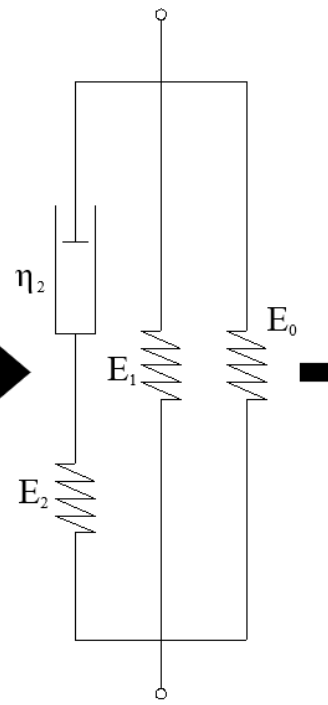

(b)

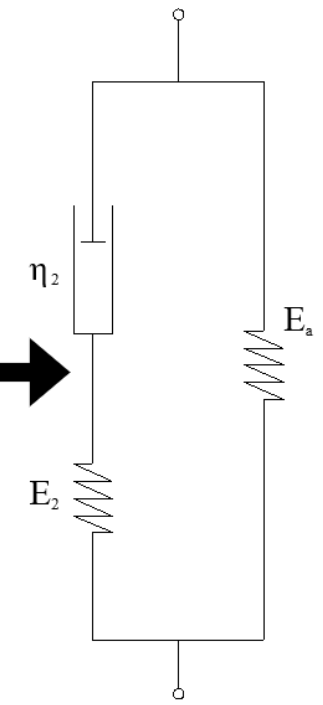

(c)

Figure 1. The expression of Z-W-T nonlinear viscoelastic model. The expression of Z-W-T nonlinear viscoelastic model. (a) The main expression of the Z-W-T non-linear viscoelastic model. (b) The approximately converting of part I in Equation (1). (c) Re-place the low-frequency Maxwell element in the Z-W-T non-linear viscoelastic mode.

\subsection{The Modified Z-W-T Nonlinear Viscoelastic Model}

The Z-W-T nonlinear viscoelastic model can be improved by considering how the dynamic mechanical properties of polypropylene concrete are affected by temperature and impact load under real-time high temperatures:

1. The initial stage of the stress-strain curve of concrete under impact loading was nearly linear elastic [29], meaning that part I of Equation (1) can be approximately converted into a linear polynomial, as shown in Equation (2).

$$
E_{0} \varepsilon+\alpha \varepsilon^{2}+\beta \varepsilon^{3} \rightarrow E_{0} \varepsilon
$$

2. Part II of Equation (1) consists of two Maxwell element relaxation functions and have large differences in the relaxation time $\left(\theta_{1}\right.$ and $\left.\theta_{2}\right)$, where the Maxwell element with relaxation time $\theta_{1}$ describes the mechanical behavior of the material at a low strain rate, and the Maxwell element with relaxation time $\theta_{2}$ describes the viscoelastic behavior of 
the material at a high strain rate (the order of magnitude for $\theta_{1}$ and $\theta_{2}$ are $10 \sim 10^{2} \mathrm{~s}$ and $10^{-4} \sim 10^{-6} \mathrm{~s}$, respectively). Other studies have shown that the mechanical properties of concrete material were obviously affected by the strain rate especially and they were sensitive at high strain rates [26].The strain rate of polypropylene concrete under the impact load $10^{2} \mathrm{~s}^{-1}$ [30] resulted in a short observation time; in this case, the low-frequency Maxwell element could not be relaxed, showing linear springs characteristics, whereas the Maxwell element with a relaxation time of $\theta_{2}$ described the viscoelastic mechanical behavior of the material under high strain rate conditions. Therefore, a simple spring can be used to replace the low-frequency Maxwell element in the Z-W-T non-linear viscoelastic model in this situation (Equation (3)), and under a high strain rate, the Z-W-T nonlinear viscoelastic model can be expressed by Figure $1 \mathrm{~b}$. Equation (4) shows the equivalent treatment of two parallel elastomers and the adjusted Z-W-T nonlinear viscoelastic model (Equation (5)) is represented in Figure 1c. Although the final expression form of the modified Z-W-T nonlinear viscoelasticity model was similar to that of the Kelvin-Voigt model [31], the derivation processes of the two models were not the same.

$$
\begin{gathered}
E_{1} \int_{0}^{t} \dot{\varepsilon}(t) \exp \left(-\frac{t-\tau}{\theta_{1}}\right) d \tau \rightarrow E_{1} \varepsilon \\
E_{0} \varepsilon+E_{1} \varepsilon \rightarrow E_{a} \varepsilon \\
\sigma=E_{a} \varepsilon+E_{2} \int_{0}^{t} \dot{\varepsilon}(t) \exp \left(-\frac{t-\tau}{\theta_{2}}\right) d \tau
\end{gathered}
$$

3. As a heterogeneous material, polypropylene concrete contains a large number of random polypropylene fibers and pores [32]. Therefore, damage factors should be considered when studying dynamic damage constitutive models of polypropylene concrete under impact load and thermal conditions. From the perspective of continuous damage mechanics, polypropylene concrete is assumed to be a continuous medium [33]. The composite damage amount $\mathrm{D}$ was introduced to measure the degree of damage experienced by the polypropylene concrete. In this case, Equation (6) describes a relationship according to the principle of strain equivalence [34]. Additionally, the modified Z-W-T non-linear viscoelastic model with the damage variable D (Equation (7)) can be obtained by substituting Equation (5) into Equation (6).

$$
\sigma_{a}=(1-D) \sigma_{r}
$$

where $\sigma_{a}$ represents effective stress, $\sigma_{r}$ represents the nominal stress, and $D$ represents the damage variable.

$$
\sigma=[1-D] \times\left[E_{a} \varepsilon+E_{2} \int_{0}^{t} \dot{\varepsilon}(t) \exp \left(-\frac{t-\tau}{\theta_{2}}\right) d \tau\right]
$$

\subsection{Damage Variable}

The thermal damage to polypropylene concrete can be described using the damage accumulation method according to both the macroscopic mechanical properties and internal structure variation characteristics of the polypropylene fiber concrete sample effected by thermal conditions and the method used in heat transfer theory [10]. In the current study, there was not a uniform description method for damage accumulation, so the descriptors from [35-38] were used to evaluate the thermal damage.

In this paper, the commonly used elastic modulus ratio method was used to describe the thermal damage imparted on the structural characteristics of polypropylene concrete 
and the relevant parameters that were tested in real-time high-temperature experiments. The thermal damage $\mathrm{D}_{\mathrm{T}}$ was calculated according to Equation (8):

$$
D_{T}=1-\frac{E_{T}}{E_{0}}
$$

where $D_{T}$ represents the thermal damage factor, and $E_{T}$ and $E_{0}$ represent the dynamic elastic modulus of polypropylene concrete under high-temperature conditions and at room temperature, respectively.

It is well documented [39-41] that when materials fail under impact load, it is a time process where microdefects or microdamage evolve at a certain rate, meaning that the size of the broken material after damage decreases as the loading strain rate increases [42], which is caused by the increase in the number of microcracks that develop during failure. The experimental dynamic impact compression results for polypropylene fiber concrete showed that the damage and failure of the polypropylene fiber concrete under the impact load also conforms to this rule and shows obvious strain rate effect, indicating that the damage and failure of polypropylene fiber concrete under the impact load have a direct relationship with the strain rate. Because of this, the damage caused by the dynamic impact load on polypropylene fiber concrete can be regarded as a function that is related to the strain rate, regardless of whether the sample was under constant strain rate loading. Therefore, it was assumed that the damage degree of the internal differential element obeyed the Weibull distribution, which was used to express the damage that the polypropylene concrete experienced under an impact load that was determined based on references [43-45]:

$$
D_{M}=\frac{N_{t}}{N}
$$

where $D_{M}$ represents the damage variable, and $N_{t}$ and $N$ represent the damage number and total number of differential elements in concrete under a certain state, respectively.

It is necessary to assume that the probability density of the Weibull distribution follows the relationship in Equation (10):

$$
\phi(F)=\frac{m}{F_{0}}\left(\frac{F}{F_{0}}\right)^{m-1} \exp \left(-\left(\frac{F}{F_{0}}\right)^{m}\right)
$$

where $F$ represents the strength of the micro-element, which can be calculated by referring to reference [46], and $\mathrm{m}$ and $F_{0}$ represent the parameters related to the material properties that can be calculated by the peak limit method [47].

The random variation interval of a differential element (assumption $[\varepsilon, \varepsilon+d \varepsilon]$ ) can be used to characterize the change in the damage variable with the change in the stress state according to the assumption of the density function of the differential element in the basic assumption. It is logical that the number of damaged differential elements in a certain state can be expressed as Equation (11).

$$
N_{t}(\varepsilon)=\int_{0}^{\varepsilon} N \phi(F) d F
$$

Thus, the damage equation of polypropylene concrete under the impact load is shown in Equation (12):

$$
D_{M}=1-\exp \left(-\left(\frac{F}{F_{0}}\right)^{m}\right)
$$

The results obtained in [40] show that when considering the combined effect of temperature damage and dynamic load damage on polypropylene concrete specimens, the two kinds of damage cannot be directly superimposed on each other, but the coupling effect of the temperature damage and the dynamic load damage should be considered. 
The definition of the coupling effect of the thermal damage and dynamic load can be referred to as the stress equivalence principle [34]:

$$
D=D_{T}+D_{M}-D_{T} D_{M}
$$

The final form of the damage factor can be obtained by substituting the determined thermal damage (Equation (8)) with the dynamic load damage (Equation (12)):

$$
D=1-\frac{E_{t}}{E_{0}} \exp \left(-\left(\frac{F}{F_{0}}\right)^{m}\right)
$$

The dynamic constitutive model of polypropylene concrete that considers the thermal effect can be obtained by substituting the determined damage factor into the modified Z-W-T non-linear viscoelastic model:

$$
\sigma=\left[1-\frac{E_{t}}{E_{0}} \exp \left(-\left(\frac{F}{F_{0}}\right)^{m}\right)\right] \times\left[E_{a} \varepsilon+E_{2} \int_{0}^{t} \dot{\varepsilon}(t) \exp \left(-\frac{t-\tau}{\theta_{2}}\right) d \tau\right]
$$

where $F$ represents the strength of the micro-element, which can be calculated according to [46], $\mathrm{m}$ and $F_{0}$ represent the parameters related to material properties that can be calculated by the peak limit method [47], and the other parameters can be obtained through fitting with the experimental data.

The experimental condition under dynamic stress equalization could be regarded as constant strain rate loading in the SHPB experiment, in this case, the definite integral part (low-frequency Maxwell element) of Equation (15) could be simplified. In addition, Equation (15) could be simplified to Equation (16), subsequently.

$$
\sigma_{a}=\left[\frac{E_{T}}{E_{0}} \exp \left[-\left(\frac{F}{F_{0}}\right)^{m}\right]\right]\left\{E_{a} \varepsilon+E_{2} \theta_{2} \dot{\varepsilon}\left[1-\exp \left(-\frac{\varepsilon}{\dot{\varepsilon} \theta_{2}}\right)\right]\right\}
$$

\section{Experiment and Results}

The purpose of the experiment was to explore the dynamic mechanical properties of polypropylene fiber concrete under real-time high temperatures and to determine relevant parameters for the dynamic damage constitutive model of polypropylene fiber concrete effected by thermal conditions. The improved SHPB dynamic mechanical property test was carried out to test the dynamic impact compression of C30 PP concrete with different average impact velocity grades under different real-time temperature grades $\left(200{ }^{\circ} \mathrm{C}\right.$, $400{ }^{\circ} \mathrm{C}, 600^{\circ} \mathrm{C}$ and $800{ }^{\circ} \mathrm{C}$ ). The independent experiments were repeated three times under each engineering condition, and meaningful data were selected for the statistics in order to ensure that the experimental data were scientific. In addition, experiments were also carried out at room temperature under each average impact velocity grade, serving as a control group.

\subsection{Experimental Material}

For these experiments, Chinese national standard P.O.42.5 Portland cement produced by Yunnan Hongshi cement Co., LTD was adopted. High-quality grade II fly ash with a density of $2098 \mathrm{~kg} / \mathrm{m}^{3}$ was produced by Yunnan Power Plant from Yunnan Province was used for the experiments. The following water-binder ratio was adopted for all mixes: 0.44 . The characteristics of the polypropylene fibers used in this experimental are shown in Table 1. The proportions of the concrete samples are described in Table 2. The polypropylene fiber concrete specimens were made into $\varphi 75 \mathrm{~mm} \times 40 \mathrm{~mm}$ cylinder specimens [48], as shown in Figure 2. 
Table 1. Main performance parameters of polypropylene fiber characteristics.

\begin{tabular}{ccccccc}
\hline Characteristics & $\begin{array}{c}\text { Density } \\
\left(\mathbf{g} / \mathbf{c m}^{\mathbf{3}}\right)\end{array}$ & $\begin{array}{c}\text { Length } \\
(\mathbf{m m})\end{array}$ & $\begin{array}{c}\text { Equivalent } \\
\text { Diameter }\end{array}$ & $\begin{array}{c}\text { Melting Point } \\
\left({ }^{\circ} \mathbf{C}\right)\end{array}$ & $\begin{array}{c}\text { Elongation at Break } \\
\mathbf{( \% )}\end{array}$ & $\begin{array}{c}\text { Elastic Modulus } \\
\mathbf{( M P a})\end{array}$ \\
\hline Parameter & 1.18 & $3-9$ & $9-30 \mathrm{um}$ & 220 & $\geq 15-25$ & $\geq 13,000$ \\
\hline
\end{tabular}

Table 2. Concrete proportions $\left(\mathrm{Kg} / \mathrm{m}^{3}\right)$.

\begin{tabular}{cccccccc}
\hline Water & Cement & Fly Ash & Silica Fume & Sand & Pebble & $\begin{array}{c}\text { Polypropylene } \\
\text { Fiber }\end{array}$ & $\begin{array}{c}\text { Water Reducing } \\
\text { Admixture }\end{array}$ \\
\hline 160 & 234 & 108 & 18 & 714 & 1166 & 1 & 7.2 \\
\hline
\end{tabular}

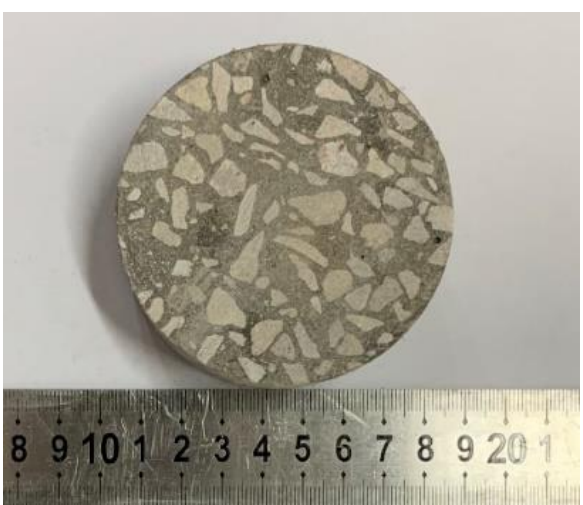

Figure 2. $\varphi 75 \mathrm{~mm} \times 40 \mathrm{~mm}$ polypropylene concrete specimen for SHPB test.

\subsection{Experimental Equipment}

The SHPB equipment conducted in the experiment is shown in Figure 3. The incident rod and the transmission rod were $\Phi 2000 \mathrm{~mm} \times 75 \mathrm{~mm}$ in size. The spindle bullet was used to adjust the waveform shape. The material parameters of the rod are given in Table 3.

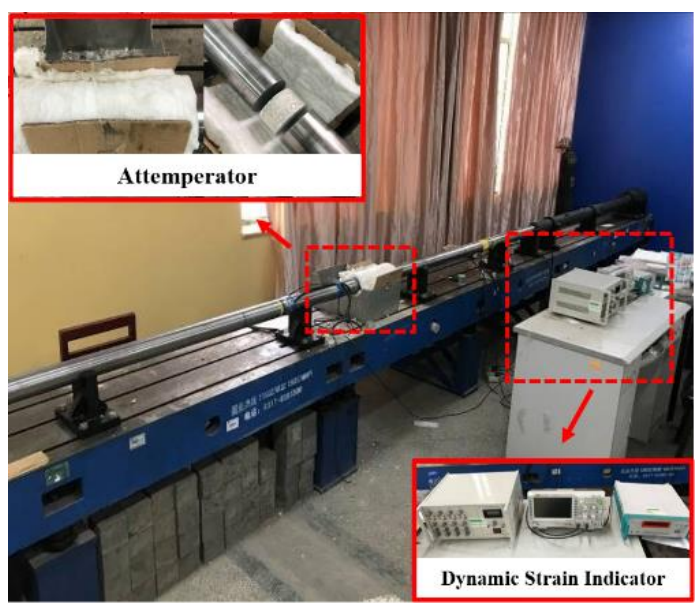

Figure 3. The SHPB equipment used in the experiment.

Table 3. Material parameters of the rod.

\begin{tabular}{cccc}
\hline Material & Density & Elastic Modulus & Poisson Ratio \\
\hline $45 \mathrm{GrNiMoVA}$ & $7794 \mathrm{~g} / \mathrm{cm}^{3}$ & $211 \mathrm{GPa}$ & 0.285 \\
\hline
\end{tabular}

In the real-time high-temperature SHPB experiment, the SHPB equipment was modified, and the insulation device was installed in the same position as the loading specimen. 
The strain gauges were positioned $1.8 \mathrm{~m}$ and $0.6 \mathrm{~m}$ away from the contact of the specimen at the incident rod and transmission rod, respectively.

In this experiment, the XH7L-12 muffle furnace produced by Zhengzhou Xinhan Instruments and Equipment Co., Ltd. was used to heat the specimens. The rated power was $5 \mathrm{~kW}$, the voltage was $380 / 220 \mathrm{~V}$, the maximum working temperature was $1200^{\circ} \mathrm{C}$, and the temperature control accuracy was $1-3{ }^{\circ} \mathrm{C}$. The furnace used special ceramic fiber materials and composite fiber materials, which were characterized by their fast heating rate, and these fibers were $300 \mathrm{~mm} \times 200 \mathrm{~mm} \times 120 \mathrm{~mm}$ (length $\times$ width $\times$ height) in size.

\subsection{The Solution of Real-Time High-Temperature Experiments}

During the heating process, the heating rate was set to $5{ }^{\circ} \mathrm{C} / \mathrm{min}$, which was chosen based on the heating method used for concrete specimens in the literature [43], and the constant temperature was maintained for $2 \mathrm{~h}$ when the temperature reached the set temperature grade. The heating curves are shown in Figure 4.

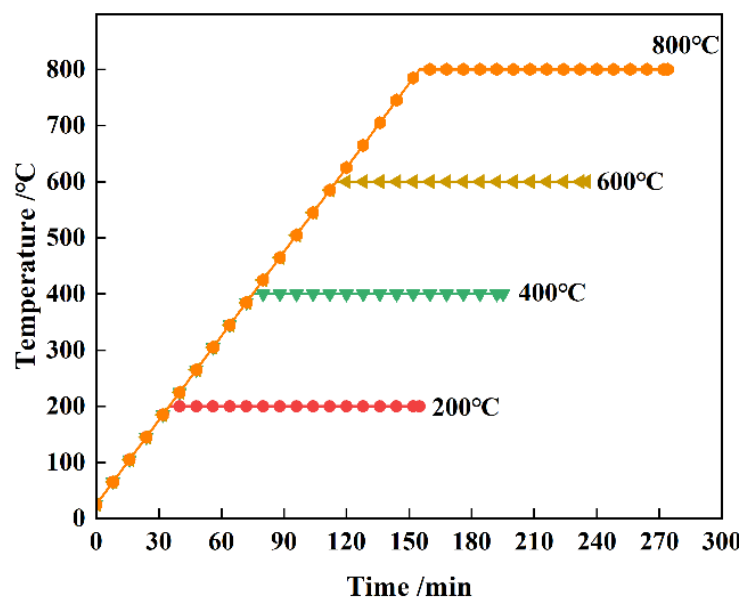

Figure 4. The heating curves.

It is well documented [49-52] that concrete is a material with poor thermal conductivity compared to other materials, such as metals, and that the temperature variation rate of concrete is much less than that of metal materials. The thermal conductivity and heat loss time were considered in order to ensure that the temperature of the concrete specimens will still be able to satisfy the requirements of the SHPB experiment.

During the SHPB test, the asbestos-wrapped specimen shown in Figure 3 was loaded on the experimental platform to reduce heat loss from the specimen into the surrounding air, ensuring that the specimen was in a relatively sealed environment, meaning that the experimental loading processes was able to be maintained at a constant temperature.

The time from the completion of heating to the completion of the SHPB experiment was measured. During the high-temperature SHPB experiment, the specimen was taken out of the furnace after it had been heated until it reached the end of the SHPH test bench, about $30 \mathrm{~s}$. The impact experiment was then carried out. The whole process, from the preparation to the end of the experiment, was about $20 \mathrm{~s}$ in total. Therefore, the time from which the specimen was taken out of the furnace to the end of the experiment was about $50 \mathrm{~s}$. Because the specimen lost heat during the process, the heating temperature should be adjusted; that is, the heating temperature should be adjusted according to $101 \sim 105 \%$ of the corresponding temperature level determined in the experimental scheme. In order to verify the real-time high-temperature solution, the temperature of the concrete specimens was measured under each of the four temperature groups.

As shown in Table 4, the temperature of the bullet impact specimen during the experiment was $32{ }^{\circ} \mathrm{C}$ lower than that of the specimen after loading. The temperature variation law of concrete specimens at various stages of the experiment was obtained. It 
was determined that the temperature of the specimen that had been heated by the electric furnace was regarded as the temperature of the whole impact experiment.

Table 4. Temperature statistics of specimen during SHPB high-temperature test $\left({ }^{\circ} \mathrm{C}\right)$.

\begin{tabular}{ccccc}
\hline Target & Removal & Before Experiment & After Experiment & Drop Rate (\%) \\
\hline 700 & 704 & 683 & 672 & 4.55 \\
500 & 503 & 489 & 483 & 3.98 \\
300 & 306 & 297 & 290 & 5.23 \\
100 & 105 & 101 & 98 & 6.67 \\
\hline
\end{tabular}

\subsection{Experiment Theory}

As shown in Figure 5, during the SHPB experiment, the stress wave and the marked incident wave $\varepsilon_{I}(t)$ were produced by the impact transmitting along the axial direction of the bar [53]. Some stress waves are reflected at the S1 interface and propagate in the opposite direction to form reflection waves $\varepsilon_{R}(t)$, and the residual stress waves continue to propagate through the specimen to form transmission waves $\varepsilon_{T}(t)$ in the transmission bar. The incident waves $\varepsilon_{I}(t)$, reflection waves $\varepsilon_{R}(t)$, and transmission waves $\varepsilon_{T}(t)$ were collected by strain gauges $\mathrm{A}$ and $\mathrm{B}$, which were attached to the incident rod and transmission rod, respectively.

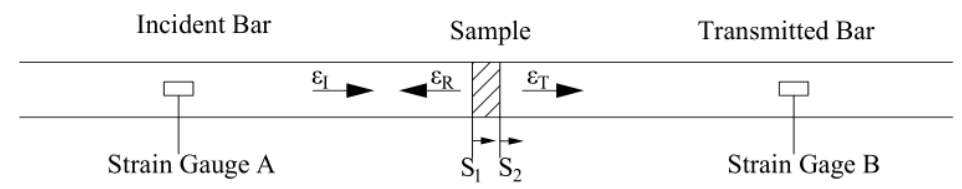

Figure 5. Deformation and stress analysis of specimens.

The average stress, strain rate, and strain of the specimen could be calculated by Equation (17) [54].

$$
\left\{\begin{array}{l}
\sigma_{s}(t)=\frac{A E}{2 A_{s}}\left[\varepsilon_{I}(t)+\varepsilon_{R}(t)+\varepsilon_{T}(t)\right] \\
\dot{\varepsilon}(t)=\frac{C_{0}}{l_{s}}\left[\varepsilon_{T}(t)-\varepsilon_{I}(t)+\varepsilon_{R}(t)\right] \\
\varepsilon(t)=\frac{C_{0}}{l_{s}} \int_{0}^{t}\left[\varepsilon_{T}(t)-\varepsilon_{I}(t)+\varepsilon_{R}(t)\right] d t
\end{array}\right.
$$

where $A, E$, and $C_{0}$ are the cross-sectional area, the Young's modulus, and the wave velocity of the bar material, and $l_{S}$ and $A_{S}$ are the length and cross-section of the specimen.

\subsection{Typical Waveform and Dynamic Stress Equalization}

The representative original voltage signal diagram for this experiment can be seen in Figure 6. It can be observed from Figure 6 that the loading waveforms show a semisinusoidal shape and that the curves are smooth without any obvious waveform diffusion being observed. The incident wave also basically returns to the origin, and the reflected wave has a relatively smooth section, which meets the constant strain rate loading conditions $[53,55]$.

The method proposed by YIN [56] and shown in Equation (18) was applied to evaluate the dynamic stress equalization verification for the SHPB experiment of the fusiform bullet. Whether stress equalization was achieved in the SHPB experiment could be assessed by comparing the curve trends in $P_{1}$ and $P_{2}$.

$$
\left\{\begin{array}{l}
P_{1}=E_{0} A_{0}\left[\varepsilon_{i}(t)+\varepsilon_{r}(t)\right] \\
P_{2}=E_{0} A_{0}\left[\varepsilon_{t}(t)\right]
\end{array}\right.
$$

where $\varepsilon_{i}(t), \varepsilon_{r}(t)$, and $\varepsilon_{t}(t)$ represent the incident wave, reflection wave, and transmission wave, respectively. $P_{1}$ and $P_{2}$ represent the stress of $S_{1}$ and $S_{2}$, respectively. $A_{0}$ and $E_{0}$ are the cross-sectional area and elastic modulus of the bar. 


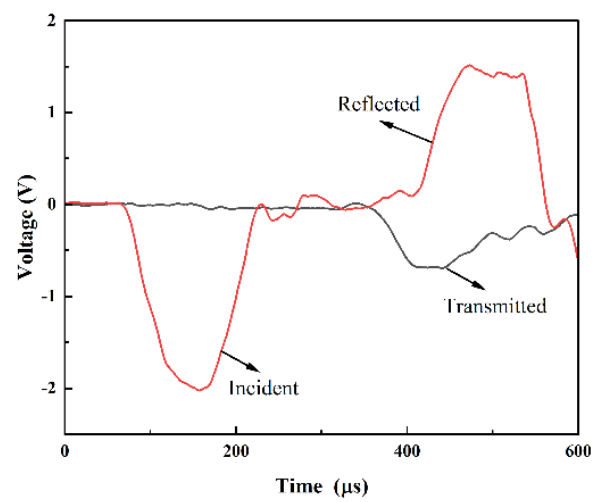

Figure 6. The representative original voltage signal diagram.

A typical stress equalization stress curve is showed in Figure 7, where it can be observed that the evolution trend in the $P_{1}$ and $P_{2}$ curves was basically consistent, proving that the constant strain rate loading condition was satisfied.

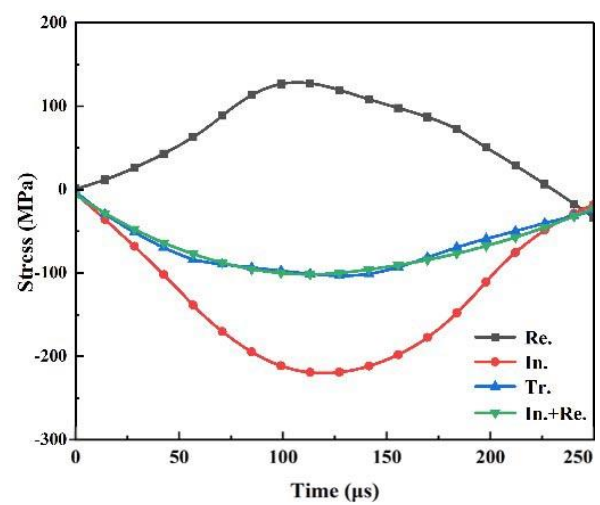

Figure 7. Typical test curve for stress equalization.

\subsection{The Relationship between Impact Air Pressure Level and Impact Velocity}

The impact velocity was determined by the impact air pressure. In order to judge the average impact velocity at different impact air pressures, experiments were carried out under no-load conditions. Table 5 showed the impact pressure at different impact air pressure levels.

Table 5. The average impact pressure at different impact air pressure levels.

\begin{tabular}{ccc}
\hline $\begin{array}{c}\text { Impact Air Pressure } \\
(\mathbf{M P a})\end{array}$ & $\begin{array}{c}\text { Impact Velocity } \\
(\mathbf{m} / \mathbf{s})\end{array}$ & $\begin{array}{c}\text { Average Impact Velocity } \\
(\mathbf{m} / \mathbf{s})\end{array}$ \\
\hline \multirow{2}{*}{0.4} & 5.6 & \\
& 5.3 & 5.5 \\
\multirow{2}{*}{0.6} & 5.5 & \\
& 7.3 & 7.5 \\
\hline \multirow{2}{*}{0.8} & 7.8 & \\
& 7.4 & 9.5 \\
\hline
\end{tabular}

\subsection{Results of Experiment}

The dynamic stress-strain curves of polypropylene concrete under different impact velocities and different temperature grades are shown in Figure 8. For the convenience of 
description, the average impact velocity under the same impact pressure was determined to be the same in this paper. Due to the limitation of the length of this paper, only one set of experiments under each working condition was selected to draw the dynamic stress-strain curves.

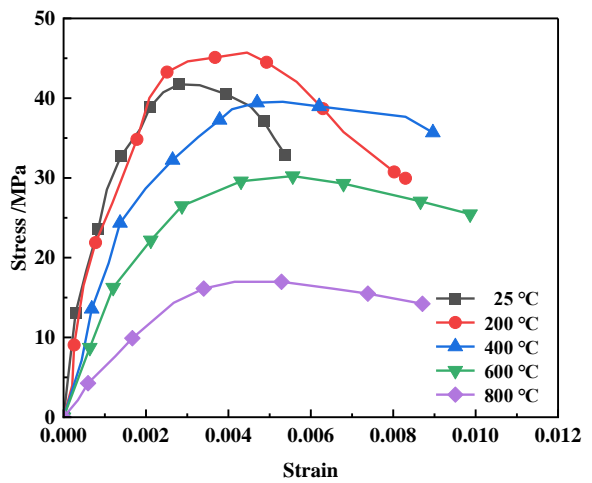

(a)

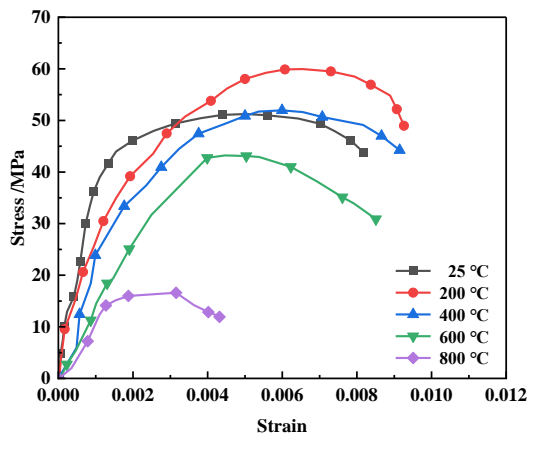

(b)

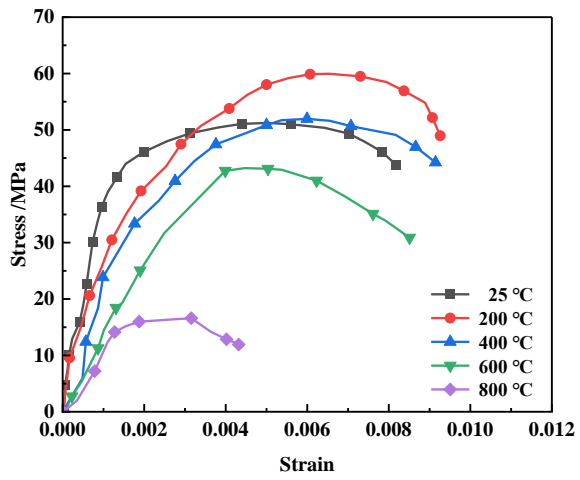

(c)

Figure 8. Dynamic stress-strain curves of polypropylene fiber concrete in different conditions. (a) Impact air pressure $=0.4 \mathrm{MPa}$, average impact $=5.5 \mathrm{~m} / \mathrm{s}$; (b) impact air pressure $=0.6 \mathrm{MPa}$, average impact $=7.5 \mathrm{~m} / \mathrm{s} ;(\mathbf{c})$ impact air pressure $=0.8 \mathrm{MPa}$, average impact $=9.5 \mathrm{~m} / \mathrm{s}$.

It can be observed from Figure 8 that the dynamic stress-strain curves of polypropylene concrete under real-time high-temperature conditions have similar trends, which can be roughly divided into four stages: the linear elastic stage, plastic yield stage, failure stage, and post-failure stage. At the same time, by comparing the dynamic stress-strain curves of the polypropylene concrete at different temperature levels under different average impact velocities, it can be observed that the dynamic compression mechanical properties of polypropylene concrete have an obvious temperature effect and strain rate effect. As the temperature level increases, the peak stress first increases and then decreases, and the slope of the linear elastic stage decreases continuously.

\section{Discussion}

\subsection{Effect of Thermal Conditions on Dynamic Mechanical Properties of Polypropylene Fiber Concrete}

The average dynamic compressive strength and average elastic modulus of polypropylene concrete under different temperature levels and different impact pressure levels are showed in Figure 9.

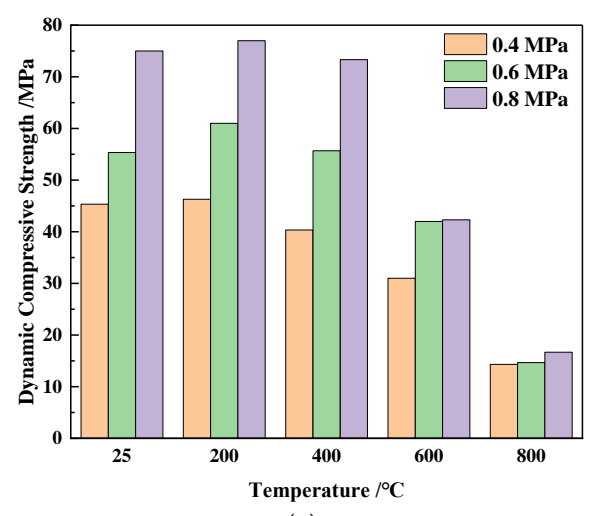

(a)

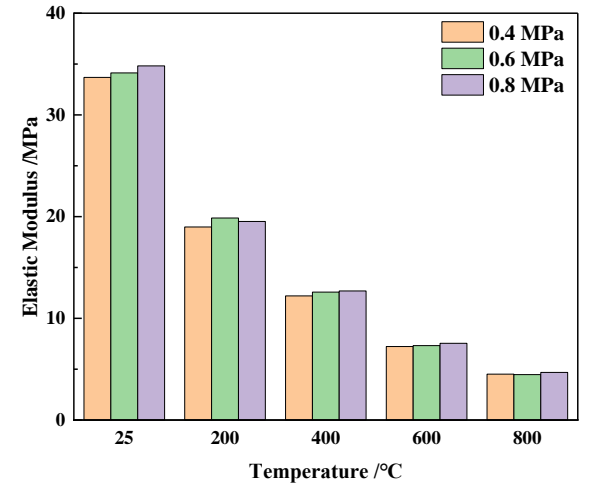

(b)

Figure 9. Effect of thermal conditions on dynamic mechanical properties of polypropylene fiber concrete. (a) Average dynamic compressive strength of polypropylene concrete under different conditions. (b) Average elastic modulus of polypropylene concrete under different conditions. 
It can be observed from Figure 9a that under the action of temperature load, the dynamic compressive strength of polypropylene fiber concrete was not monotonically linear as the temperature grade increased. For example, with an impact air pressure $0.4 \mathrm{MPa}$ (average impact velocity $=5.5 \mathrm{~m} / \mathrm{s}$ ), compared with the case at $25^{\circ} \mathrm{C}$, the dynamic compressive strength of polypropylene fiber concrete at $200{ }^{\circ} \mathrm{C}$ increases by $10.2 \%$, and compared with the case at $200^{\circ} \mathrm{C}$, the dynamic compressive strength of polypropylene fiber concrete at $400{ }^{\circ} \mathrm{C}, 600{ }^{\circ} \mathrm{C}$ and $800{ }^{\circ} \mathrm{C}$ decreases by $8.73 \%, 31.14 \%$ and $72.59 \%$, respectively. It seemed that there was a threshold temperature grade; when the temperature grade was lower than this threshold, the dynamic strength of polypropylene fiber concrete increased as the temperature grade increased, and when the temperature grade was higher than this threshold, the opposite situation takes place. In this experiment, the threshold was between $200^{\circ} \mathrm{C}$ and $400{ }^{\circ} \mathrm{C}$. It also can be observed from Figure $9 \mathrm{~b}$ that the elastic modulus of polypropylene concrete under different temperature grades decreased as the thermal grade increased and that it reached its minimum at $800^{\circ} \mathrm{C}$. Although the dynamic elastic modulus showed an improvement when the impact pressure level increased, the strain rate effect of the elastic modulus is not as obvious compared to the strain rate effect of the dynamic compressive strength.

Other relevant studies from the literature [56-60] have used microscopic observation technology to study the internal components, structure, and other microscopic aspects of fiber concrete exposed to high temperatures. The research results can explain the experimental phenomenon well: before the threshold temperature, as the temperature increases, part of the water that had been combined with the concrete decomposed due to the high temperatures, promoting the further hydration of the unhydrated cement particles [60]. The polypropylene fibers gradually dissolved, and the dissolved polypropylene fibers played a role in filling the original pores, improving the strength. When the temperature exceeded a certain range, due to the continuous escape of the water in the concrete, hydrated calcium silicate gel and calcium hydroxide decomposed and dehydrated at different temperatures, and the original microcracks continued to develop under the high-temperature conditions, resulting in the original dense structure gradually becoming looser over time, resulting in reduced strength.

\subsection{Validation of Constitutive Model and Determination of Parameters}

The values of the $\mathrm{m}$ and $\mathrm{F}_{0}$ parameters in the dynamic damage constitutive model of polypropylene concrete at the different experimental conditions that were calculated are shown in Table 5. The other model parameters could be determined by using data fitting software combined with the experimental data after the determined values were substituted into the model. Figure 10 shows the fitting results of the dynamic damage constitutive model of polypropylene concrete in different conditions, and the parameter values that obtained by fitting were shown in Table 6 .

It can be observed from the fitting results in Figure 10 that the model can describe the dynamic stress-strain curves of polypropylene concrete, and the variation rules of the thermal effect and strain rate effect under different conditions were also consistent with the experimental data. However, the fitting effect was not consistent under each condition. Compared to the higher impact pressure level, the fitting effect of the model was better under the impact pressure grade of $0.4 \mathrm{MPa}$ and the impact pressure grade of $0.6 \mathrm{MPa}$, which could be the result of the different concrete failure processes that the specimens experienced under the higher strain rates. 


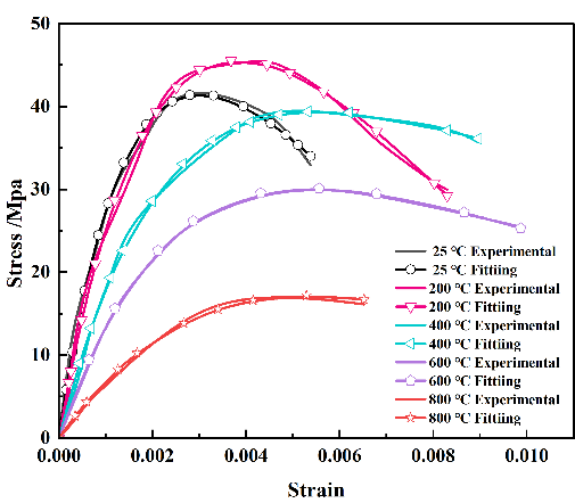

(a)

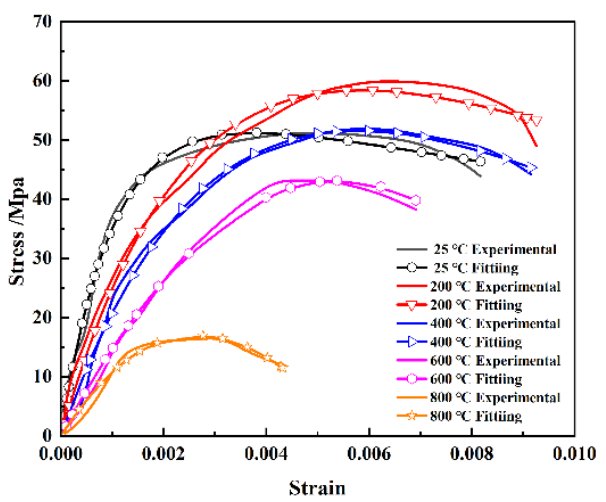

(b)

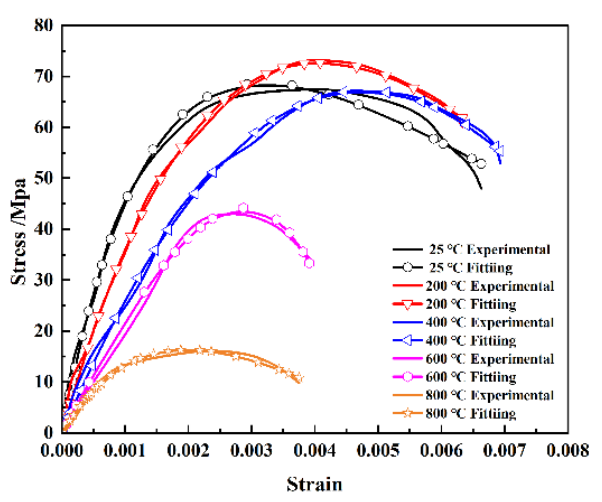

(c)

Figure 10. The fitting curves of polypropylene concrete in different conditions. (a) Impact air pressure $=0.4 \mathrm{MPa}$, average impact $=5.5 \mathrm{~m} / \mathrm{s} ;(\mathbf{b})$ impact air pressure $=0.6 \mathrm{MPa}$, average impact $=7.5 \mathrm{~m} / \mathrm{s} ;(\mathbf{c})$ impact air pressure $=0.8 \mathrm{MPa}$, average impact $=9.5 \mathrm{~m} / \mathrm{s}$.

Table 6. Parameter values under different experimental conditions.

\begin{tabular}{|c|c|c|c|c|c|c|c|}
\hline \multirow{2}{*}{$\begin{array}{l}\text { Average Impact } \\
\text { Air Pressure }\end{array}$} & \multirow{2}{*}{$\begin{array}{c}\text { Temperature } \\
\text { Grade }\end{array}$} & \multicolumn{2}{|c|}{ Calculated Parameters } & \multicolumn{3}{|c|}{ Fitting Parameters } & \multirow{2}{*}{$\mathbf{R}^{2}$} \\
\hline & & $\mathbf{m}$ & $\mathrm{F}_{0}$ & $\mathrm{E}_{\mathbf{a}}$ & $\mathrm{E}_{2}$ & $\theta_{2}$ & \\
\hline \multirow{5}{*}{0.4} & 25 & 1.36 & 43.23 & 1.27 & -1.39 & 1.79 & 0.925 \\
\hline & 200 & 1.69 & 41.61 & 5.25 & -4.51 & 1.56 & 0.948 \\
\hline & 400 & 2.11 & 33.65 & 3.19 & -3.35 & 2.45 & 0.964 \\
\hline & 600 & 4.01 & 20.51 & 2.21 & -1.87 & 3.60 & 0.915 \\
\hline & 800 & 3.92 & 9.56 & 1.48 & -2.65 & 2.67 & 0.939 \\
\hline \multirow{6}{*}{0.6} & 25 & 1.41 & 52.39 & 1.54 & -3.32 & 2.41 & 0.959 \\
\hline & 200 & 1.97 & 51.16 & 4.87 & -1.65 & 2.86 & 0.926 \\
\hline & 400 & 3.47 & 38.76 & 4.36 & -3.78 & 3.75 & 0.959 \\
\hline & 600 & 4.48 & 25.35 & 4.23 & -5.23 & 3.55 & 0.927 \\
\hline & 800 & 4.29 & 8.61 & 6.79 & -5.11 & 1.37 & 0.949 \\
\hline & 25 & 1.94 & 64.42 & 1.76 & -2.45 & 1.27 & 0.913 \\
\hline \multirow{4}{*}{0.8} & 200 & 2.58 & 61.15 & 1.53 & -3.12 & 1.53 & 0.914 \\
\hline & 400 & 3.66 & 45.36 & 1.04 & -2.12 & 3.69 & 0.981 \\
\hline & 600 & 4.12 & 37.61 & 1.86 & -3.13 & 5.49 & 0.971 \\
\hline & 800 & 4.24 & 21.23 & 1.29 & -2.76 & 1.42 & 0.915 \\
\hline
\end{tabular}

\section{Conclusions}

In this paper, the dynamic mechanical properties of polypropylene fiber concrete were tested under different thermal grades and different impact rates using improved SHPB equipment. A dynamic damage constitutive model of polypropylene fiber concrete that considered thermal effects was constructed according to the dynamic mechanical properties of polypropylene concrete under real-time high-temperature conditions. The main conclusions are as follows:

A dynamic damage constitutive model of polypropylene concrete considering thermal effects based on the Z-W-T nonlinear viscoelastic model was established. The model considered the damage to polypropylene concrete caused by thermal conditions and the coupling effect of the temperature and impact load.

There was an obvious thermal effect in the dynamic mechanical properties of polypropylene concrete. The dynamic elastic modulus of the polypropylene concrete decreased as the temperature grade increased. The effect of thermal on dynamic compressive strength was different: there was a threshold temperature grade, when the temperature grade was lower than this threshold, then the dynamic strength of polypropylene fiber concrete in-creased as the temperature grade increased, and when the temperature grade was higher than this 
threshold, the opposite situation takes place. In this paper, the threshold temperature grade was between $200{ }^{\circ} \mathrm{C}$ and $400{ }^{\circ} \mathrm{C}$.

Compared with the experimental data, it was determined that the model can describe the stress-strain curves of polypropylene concrete under different conditions well. The temperature effect and strain rate effect shown by the fitting curves are consistent with the experimental data.

Author Contributions: R.L., H.A. and L.L. designed the experiments; R.L. and Y.W. carried out the experiments; R.L. analyzed the experimental results. L.L. analyzed data and developed the analysis tools. R.L. wrote the manuscript. All authors have read and agreed to the published version of the manuscript.

Funding: This research was funded by National Natural Science Foundation of China (grant nos.11862010 and 51964023).

Institutional Review Board Statement: Not applicable.

Informed Consent Statement: Not applicable.

Data Availability Statement: The data used to support the findings of this study are included within the article.

Conflicts of Interest: The authors declare no conflict of interest.

\section{References}

1. Wu, H.; Lin, X.; Zhou, A. A review of mechanical properties of fibre reinforced concrete at elevated temperatures. Cem. Concr. Res. 2020, 135, 106117. [CrossRef]

2. Yu, Q.; Zhuang, W.; Shi, C. Research progress on the dynamic compressive properties of ultra-high performance concrete under high strain rates. Cem. Concr. Compos. 2021, 124, 104258. [CrossRef]

3. Ramezani, M.; Kim, Y.H.; Sun, Z. Elastic modulus formulation of cementitious materials incorporating carbon nanotubes: Probabilistic approach. Constr. Build. Mater. 2020, 274, 122092. [CrossRef]

4. Ramezani, M.; Kim, Y.H.; Sun, Z. Mechanical properties of carbon-nanotube-reinforced cementitious materials: Database and statistical analysis. Mag. Concr. Res. 2020, 72, 1047-1071. [CrossRef]

5. Ramezani, M.; Kim, Y.H.; Sun, Z. Probabilistic model for flexural strength of carbon nanotube reinforced cement-based materials. Compos. Struct. 2020, 253, 112748. [CrossRef]

6. Xu, F.; Wang, S.; Li, T.; Liu, B.; Li, B.; Zhou, Y. Mechanical properties and pore structure of recycled aggregate concrete made with iron ore tailings and polypropylene fibers. J. Build. Eng. 2020, 33, 101572. [CrossRef]

7. Chen, Y.; Cen, G.; Cui, Y. Comparative analysis on the anti-wheel impact performance of steel fiber and reticular polypropylene synthetic fiber reinforced airport pavement concrete under elevated temperature aging environment. Constr. Build. Mater. 2018, 192, 818-835. [CrossRef]

8. Afroughsabet, V.; Ozbakkaloglu, T. Mechanical and durability properties of high-strength concrete containing steel and polypropylene fibers. Constr. Build. Mater. 2015, 94, 73-82. [CrossRef]

9. Tan, S.; Moinuddin, K. Systematic review of human and organizational risks for probabilistic risk analysis in high-rise buildings. Reliab. Eng. Syst. Saf. 2019, 188, 233-250. [CrossRef]

10. Ulm, F.-J.; Coussy, O.; Bažant, Z.P. The "Chunnel” Fire. I: Chemoplastic Softening in Rapidly Heated Concrete. J. Eng. Mech. 1999, 125, 272-282. [CrossRef]

11. Feih, S.; Mathys, Z.; Gibson, A.G.; Mouritz, A.P. Modelling the tension and compression strengths of polymer laminates in fire. Compos. Sci. Technol. 2007, 67, 551-564. [CrossRef]

12. Sukontasukkul, P.; Pomchiengpin, W.; Songpiriyakij, S. Post-crack (or post-peak) flexural response and toughness of fiber reinforced concrete after exposure to high temperature. Constr. Build. Mater. 2010, 24, 1967-1974. [CrossRef]

13. Ramezani, M.; Kim, Y.H.; Sun, Z. Modeling the mechanical properties of cementitious materials containing CNTs. Cem. Concr. Compos. 2019, 104, 103347. [CrossRef]

14. Tang, C.-W. Modeling Uniaxial Bond Stress-Slip Behavior of Reinforcing Bars Embedded in Concrete with Different Strengths. Materials 2021, 14, 783. [CrossRef]

15. Li, Y.; Yang, E.-H.; Tan, K.H. Flexural behavior of ultra-high performance hybrid fiber reinforced concrete at the ambient and elevated temperature. Constr. Build. Mater. 2020, 250, 118487. [CrossRef]

16. Park, K.S.; Shoukat, T.; Yoo, P.J.; Lee, S.H. Strengthening of hybrid glass fiber reinforced recycled hot-mix asphalt mixtures. Constr. Build. Mater. 2020, 258, 118947. [CrossRef]

17. Behnood, A.; Ghandehari, M. Comparison of compressive and splitting tensile strength of high-strength concrete with and without polypropylene fibers heated to high temperatures. Fire Saf. J. 2009, 44, 1015-1022. [CrossRef] 
18. Fu, Q.; Bu, M.; Xu, W.; Chen, L.; Li, D.; He, J.; Kou, H.; Li, H. Comparative analysis of dynamic constitutive response of hybrid fibre-reinforced concrete with different matrix strengths. Int. J. Impact Eng. 2020, 148, 103763. [CrossRef]

19. Wen, Y.; Huang, R.; Li, P.; Ma, J.; Xiao, K. Damage Evolution Equation of Concrete Materials at High Temperatures and High Strain Rates. Chin. J. High Press. Phys. 2021, 35, 54-63. (In Chinese)

20. Wang, B.; Wang, F.; Wang, Q. Damage constitutive models of concrete under the coupling action of freeze-thaw cycles and load based on Lemaitre assumption. Constr. Build. Mater. 2018, 173, 332-341. [CrossRef]

21. Zhu, Z.; Xu, D.; Wang, L. Thermoviscoelastic Constitutive Equation and Time-Temperature Equivalence of Epoxy Resin at High Strain Rates. J. Ningbo Univ. (Nat. Sci. Eng. Ed.) 1988, 1, 58-68.

22. Zhu, Z.-W.; Ning, J.-G.; Liu, X. Dynamic Mechanical Behaviors of Soil under Impact Loads. Chin. J. High Press. Phys. 2011, 25, $444-450$.

23. Liu, H.; Ning, J. Constitutive model for concrete subjected to impact loading. J. Southeast Univ. (Engl. Ed.) 2012, $28,79-84$.

24. Xie, L.; Zhao, G.; Meng, X. Research on Damage Viscoelastic Dynamic Constitutive Model of Soft Rock and Concrete Materials. Chin. J. Rock Mech. Eng. 2013, 32, 857-864.

25. Zhang, H.; Wang, B.; Xie, A.; Qi, Y. Experimental study on dynamic mechanical properties and constitutive model of basalt fiber reinforced concrete. Constr. Build. Mater. 2017, 152, 154-167. [CrossRef]

26. Yang, W.W.; Liu, H.F.; Ning, J.G. Dynamic Constitutive Model of Concrete. Adv. Mater. Res. 2012, 450, 379-382. [CrossRef]

27. Zhai, Y.; Li, Y.; Li, Y.; Wang, S.; Liu, Y.; Song, K.I. Impact of high-temperature-water cooling damage on the mechanical properties of concrete. Constr. Build. Mater. 2019, 215, 233-243. [CrossRef]

28. Wang, L. Adcanced in Impact Dynamics; China University of Science and Technology Press: Hefei, China, 1992.

29. Khosravani, M.R.; Weinberg, K. A review on split Hopkinson bar experiments on the dynamic characterisation of concrete. Constr. Build. Mater. 2018, 190, 1264-1283. [CrossRef]

30. Zhang, H.; Wang, L.; Zheng, K.; Bakura, T.J.; Jibrin, T.; Totakhil, P.G. Research on compressive impact dynamic behavior and constitutive model of polypropylene fiber reinforced concrete. Constr. Build. Mater. 2018, 187, 584-595. [CrossRef]

31. Farno, E.; Baudez, J.-C.; Eshtiaghi, N. Comparison between classical Kelvin-Voigt and fractional derivative Kelvin-Voigt models in prediction of linear viscoelastic behaviour of waste activated sludge. Sci. Total Environ. 2018, 613-614, 1031-1036. [CrossRef]

32. Gencel, O.; Kazmi, S.M.S.; Munir, M.J.; Kaplan, G.; Bayraktar, O.Y.; Yarar, D.O.; Karimipour, A.; Ahmad, M.R. Influence of bottom ash and polypropylene fibers on the physico-mechanical, durability and thermal performance of foam concrete: An experimental investigation. Constr. Build. Mater. 2021, 306, 124887. [CrossRef]

33. Xi, Y.; Eskandari-Ghadi, M.; Suwito; Sture, S. Damage Theory Based on Composite Mechanics. J. Eng. Mech. 2006, 132, 1195-1204. [CrossRef]

34. Lemaitre, J. A Course on Damage Mechanics; Springer: Berlin, Heidelberg, 1992.

35. Wang, M.; Hu, Y.; Tong, J.; Wang, Q.; Wang, Y.; Dong, C. Experimental study on shear mechanical properties and thermal damage model of shotcrete-rock interfaces under variable high temperatures. Chin. J. Rock Mech. Eng. 2019, 38, 63-75.

36. Yao, Y.; Guo, H.; Tan, K. An elastoplastic damage constitutive model of concrete considering the effects of dehydration and pore pressure at high temperatures. Mater. Struct. 2020, 53, 19. [CrossRef]

37. Zhao, D.; Zhao, R.; Jia, P.; Liu, H. Microstructure and fatigue performance of high strength concrete under compression after exposure to elevated temperatures. Eur. J. Environ. Civ. Eng. 2019, 23, 1-25. [CrossRef]

38. Huang, S.; Xia, K. Effect of heat-treatment on the dynamic compressive strength of Longyou sandstone. Eng. Geol. 2015, 191, 1-7. [CrossRef]

39. Gao, G. Influence and Revision of Transverse Inertia Effect and Pressure Hardening Effect on Strain-Rate Hardening Effect of Compressive Strength of Concrete. Trans. Beijing Inst. Technol. 2020, 40, 135-149.

40. Luo, Y.; Li, X.; Wang, Q.; Yang, J. Research Progress in Dynamic Constitutive Relationship of Polyvinyl Alcohol Fiber Reinforced Cement Matrix Composites (ECC). Contemp. Chem. Ind. 2021, 50, 1690-1697.

41. Zhai, Y.; Zhao, R.; Li, Y.; Li, Y.; Meng, F.; Wang, T. Stochastic inversion method for dynamic constitutive model of rock materials based on improved DREAM. Int. J. Impact Eng. 2021, 147, 103739. [CrossRef]

42. Xu, S.; Wu, P.; Zhou, F.; Jiang, X.; Chen, B.K.; Li, Q.H. A dynamic constitutive model of ultra high toughness cementitious composites. J. Zhejiang Univ.-Sci. A 2020, 21, 939-960. [CrossRef]

43. Fu, Q.; Xu, W.; Bu, M.; Su, L.; He, J.; Kou, H. A Simplified Dynamic Constitutive Model for Bfrcac under Confining Pressure Considering the Coupling Effect of Fibre Reinforcement and Mechanical Damage. Compos. Struct. 2021, 268, 113944. [CrossRef]

44. Wang, Z.-L.; Liu, Y.-S.; Shen, R. Stress-strain relationship of steel fiber-reinforced concrete under dynamic compression. Constr. Build. Mater. 2008, 22, 811-819. [CrossRef]

45. Yin, T.; Wang, P.; Yang, J.; Li, X. Mechanical Behaviors and Damage Constitutive Model of Thermally Treated Sandstone under Impact Loading. IEEE Access 2018, 6, 72047-72062. [CrossRef]

46. Zheng, Y.; Shi, H.; Liu, X.; Zhang, W. Failure characteristics and constitutive model of coal rock at different strain rates. Explos. Shock. Waves 2021, 41, 45-57.

47. Zhang, H.; Liu, Y.; Sun, H.; Wu, S. Transient dynamic behavior of polypropylene fiber reinforced mortar under compressive impact loading. Constr. Build. Mater. 2016, 111, 30-42. [CrossRef]

48. Huo, J.; He, Y.; Xiao, L.; Chen, B.S. Experimental Study on Dynamic Behaviours of Concrete After Exposure to High Temperatures Up to 700 a Degrees C. Mater. Struct. 2013, 46, 255-265. [CrossRef] 
49. Bentz, D.P.; Flynn, D.R.; Kim, J.H.; Zarr, R.R. A slug calorimeter for evaluating the thermal performance of fire resistive materials. Fire Mater. 2005, 30, 257-270. [CrossRef]

50. Lucio-Martin, T.; Roig-Flores, M.; Izquierdo, M.; Alonso, M. Thermal conductivity of concrete at high temperatures for thermal energy storage applications: Experimental analysis. Sol. Energy 2020, 214, 430-442. [CrossRef]

51. Zhang, T.; Zhang, Y.; Zhu, H.; Yan, Z. Characterizing the thermal properties of hybrid polypropylene-steel fiber reinforced concrete under heat exposure: Insights into fiber geometry and orientation distribution. Compos. Struct. 2021, $275,114457$. [CrossRef]

52. Tasdemir, C.; Sengul, O.; Tasdemir, M.A. A comparative study on the thermal conductivities and mechanical properties of lightweight concretes. Energy Build. 2017, 151, 469-475. [CrossRef]

53. Song, L.; Hu, S.-S. Stress uniformity and constant strain rate in SHPB test. Explos. Shock. Waves 2005, 3, $207-216$.

54. Song, L.; Hu, S.-S. Two-wave and three-wave method in SHPB data processing. Explos. Shock. Waves 2005, 4, 368-373.

55. Merle, R.; Zhao, H. On the errors associated with the use of large diameter SHPB, correction for radially non-uniform distribution of stress and particle velocity in SHPB testing. Int. J. Impact Eng. 2006, 32, 1964-1980. [CrossRef]

56. Yin, T.; Wang, C.; Wu, Y.; Wu, B. A waveform modification method for testing dynamic properties of rock under high temperature. J. Rock Mech. Geotech. Eng. 2021, 13, 833-844. [CrossRef]

57. Yang, Y.; Wu, C.; Liu, Z.; Liang, X.; Xu, S. Experimental Investigation on the Dynamic Behaviors of UHPFRC after Exposure to High Temperature. Constr. Build. Mater. 2019, 227, 116679. [CrossRef]

58. Qian, Y.; Yang, D.; Xia, Y.; Gao, H.; Ma, Z. Transport Properties and Resistance Improvement of Ultra-High Performance Concrete (UHPC) after Exposure to Elevated Temperatures. Buildings 2021, 11, 416. [CrossRef]

59. Li, Y.; Du, P.; Tan, K.H. Fire resistance of ultra-high performance concrete columns subjected to axial and eccentric loading. Eng. Struct. 2021, 248, 113158. [CrossRef]

60. Jiang, H.-P.; Jiang, A.-N.; Yang, X.-R. Statistical damage constitutive model of high temperature rock based on Weibull distribution and its verification. Rock Soil Mech. 2021, 42, 1894-1902. 